\title{
The principles of complexed multi-scale geodynamic monitoring of natural and technogenic processes
}

\author{
Pavel Anikin ${ }^{1 *}$, Iuliia Fedotova ${ }^{2}$, Gennady Kursakin ${ }^{1}$ and Mikhail Lomov ${ }^{2}$ \\ ${ }^{1}$ Mining Institute FEB RAS, Laboratory of Geomechanic, 680000 Turgeneva st. 51, Russia \\ ${ }^{2}$ Mining Institute FEB RAS, Laboratory of the digital research methods of natural and technical \\ systems, 680000 Turgeneva st. 51, Russia
}

\begin{abstract}
The principles of complexed geodynamic monitoring on the basis of long-term experience and research results of natural and manmade processes in the uranium deposits of the Streltsovsky ore province are proposed. The principles are to use simultaneously regular satellite, geodetical, seismical, geophysical, geological, and a number of other observations aimed at studying the upper part of the earth's crust. In the world's mining practice, such large-scale integrated studies, where within the boundaries of one territory (a group of deposits or ore provinces) a similar set of observations aimed at monitoring geodynamic processes in the upper part of the earth's crust has not been found. The development of monitoring methods at the "Geodynamic polygon of the Streltsovsky ore field" and the additional placement of new multi-level monitoring systems will provide more information about the state of the rock mass in the upper part of the earth's crust, increase the reliability in prediction of dangerous geodynamic manifestations, identify their precursors and reduce the risk of man-made disasters. It is planned to create a common centre for processing and analysis of multiparameter data on geodynamic processes in the depth of the rock mass and local geomechanical processes near underground mine workings.
\end{abstract}

\section{Introduction}

Intensive and large-scale activity of mining enterprises in the underground mining of rockburst-hazardous deeply embedded ore deposits affects the change in mechanical stresses in the upper part of the earth's crust. These changes are accompanied by irreversible geomechanical processes and dangerous geodynamic phenomena (rockburst and tectonic bumps, mining induced seismicity). The prediction of the dangerous geodynamic phenomena is an urgent and complex task, due to many factors and causes such as complicated geological and technological conditions of mining.

\footnotetext{
*Corresponding author: pav.anik@mail.ru
} 
Reducing the risk of the dangerous geodynamic phenomena occurrence caused by manmade impact in the area of groups of developed deposits is an important issue for a number of regions of our country, including the ore province of South-Eastern Trans-Baikal, where Priargunsky Industrial Mining and Chemical Union (Priargunsky) PIMCU PJSC conducts intensive and large-scale ore mining by using the open-pit and underground methods. Uranium deposits are concentrated at the Streltsovsky ore field (SOF), which is part of the Tulukuevsky volcanic structure with high natural seismicity. The part of the deposit located beneath the current mining workings is not sufficiently studied in terms of geomechanics to fully understand all the occurring geodynamic processes.

The most effective method for studying natural and man-made processes in the rock mass for such conditions is the organization of complex multi-level monitoring observations based on a number of methods aimed at studying the upper part of the earth's crust [1-4]. The basis for prediction the dangerous geodynamic phenomena and irreversible technological processes in the geological environment are regular data of automated measuring systems, combined into a common information base.

\section{Object and methods of research}

In 2014, on the initiative of the academic institutions of the Russian Academy of Sciences (MI FEB RAS, Khabarovsk and IGEM RAS, Moscow) with the support of management and specialists of PIMCU PJSC implemented a comprehensive program of scientific research. The purpose of the program was to create a multilevel system of complexed geomechanical and geodynamic monitoring - "Geodynamic polygon of the Streltsovsky ore field" (SOF GDP) on deposits area of the Streltsovsky ore field [5, 6].

Technical means of SOF GDP are based on a number of methods, which include: traditional geodetic measurements and GPS-control, seismic and deformation control, numerical simulation of geomechanical processes by the finite element method, local and basic geomechanical (core disking analysis) measurements. These means have different scales and provide an effective check on the number of parameters (the geo-acoustic, microseismic, deformation, etc.).

As it was noted earlier [7] the monitoring tools include SOF GDP are:

- Multi-channel automated system for acoustic monitoring of rock pressure (MSAMRP) "Prognoz-ADS", allowing to detect and to identify the parameters of SAE events with energies from 0.01 to $100 \mathrm{~kJ}$ in the frequency range of $0.5-12 \mathrm{kHz}$; MSAMRP on of the Antey deposit rockburst prone and dangerous is installed (contributing 35 receiving transducers); the software package of the monitoring system makes it possible to identify acoustically active zones, calculate their parameters, assess the geomechanical state of the rock mass and build short-term predicts of dangerous geodynamic phenomena [8].

- Acoustic broadband system of control of mining pressure (ABSCMP) "Prognoz-S", controls the phase of rock Streltsovsky and Antey deposits, with a volume of $12 \mathrm{~km}^{3}$ and registers acoustic events with energies up to $100 \mathrm{MJ}$ in the frequency range from $100 \mathrm{~Hz}$ to $1000 \mathrm{~Hz}$; software complex of monitoring system allows to detect seismic-acoustic active areas, calculate their parameters, to assess the geomechanical state of the rock mass and to build short-term predict of dangerous geodynamic phenomena; within the two fields with 12 seismic stations [9].

- Automated deformation monitoring system "ADMS" allows registering changes of deformation in the rock mass at the sites that pose a danger of stress concentration in it; according to the monitoring results, the values of mechanical stresses in the controlled area of the massif or element of rock structures are estimated [10].

- Automated station "Laser strainmeter", which allows to measure the strains of the earth's crust in the frequency range from 0 to $1000 \mathrm{~Hz}$ at the level of nanometers; the $50 \mathrm{~m}$ 
single-arm waveguide station is equipped with a nanobarograph and a high-precision temperature sensor; the equipment of the station is located at a depth of $350 \mathrm{~m}$ from the surface in underground mine workings of the Streltsovskoe deposits [11-13].

- Regional network of 5 stations for surface GPS-observations of crustal block movements relative to each other on tectonic faults; the results observations are included in the general database on the territory of South-Eastern Trans-Baikal [14].

- Data analysis software packages for mathematical modeling of stress-strain state of rocks "Sigma GT" and tectonophysical modeling on "ArcGIS 10" platform with "ArcGIS 3D-Analyst" module; based on the simulation results, a regional predict of geodynamic activity and kinematics of fault zones is constructed [15].

- The SOF GDP integrating platform is represented by the "MineFrame" software package designed for complex solution of a wide range of mining, geological and technological problems; the basis of visualization of the results of monitoring systems is a three-dimensional graphical core of the program, which allows to work with 3D models of objects, provides ample opportunities for display, analysis and management of mining technology [16].

- Portable devices "Prognoz-L" [17] is used to assess the rockburst-hazardous of the boundary parts of the rock mass by local methods.

- Portable laser scanning system "FARO FOCUS-3D" is used to control the deformation of the boundary parts of the rock mass. Underground observation points for periodic deformation monitoring are equipped on three lower horizons of the Antey deposit.

- Core drilling machine "DIAMEK-232" is used for geophysical research on core disking. This method is the basis for the implementation of the regulatory requirements for the conduct of mining in rockburst-hazardous conditions.

\section{Results}

The first stage of the SOF GDP research was completed in 2014. The use of modern tools and automated systems at the SOF GDP provides highly effective of predicting registration geomechanical processes. Each of the complexes has an independent database of measurements. Software packages allow for deep analysis of the parameters and show the results of monitoring, including integrating them into a 3D model of mine workings.

Databases of different monitoring systems are independent and are stored in local workplaces under remote control of the operator-analyst. The operator of monitoring systems refers to these databases for the analysis of results and to predict of geodynamic phenomena dangerous forms. It analyzes the results using a specialized software package, which includes the following software modules: data processing and interpretation program, automated systems of control of rock stress ("GeoAsoustics-ADS" for MSAMRP "Prognoz ADS" and "GeoAsoustics-S" for ABSCMP "Prognoz-S"); programs for modeling the stress-strain state of rocks "Sigma GT" by finite element method and tectonophysical modeling on the platform "ArcGIS 10" with the module "ArcGIS 3DAnalyst" (regional predict of seismic-geodynamic activity and kinematics of fault zones); the program "Strainmeter" for processing and interpreting data station "Laser strainmeter" and a nanobarograph; "MineFrame" program for visualization of monitoring and modeling results integrated into 3D model of mines. The elements of monitoring systems described above are shown in Fig.1. 


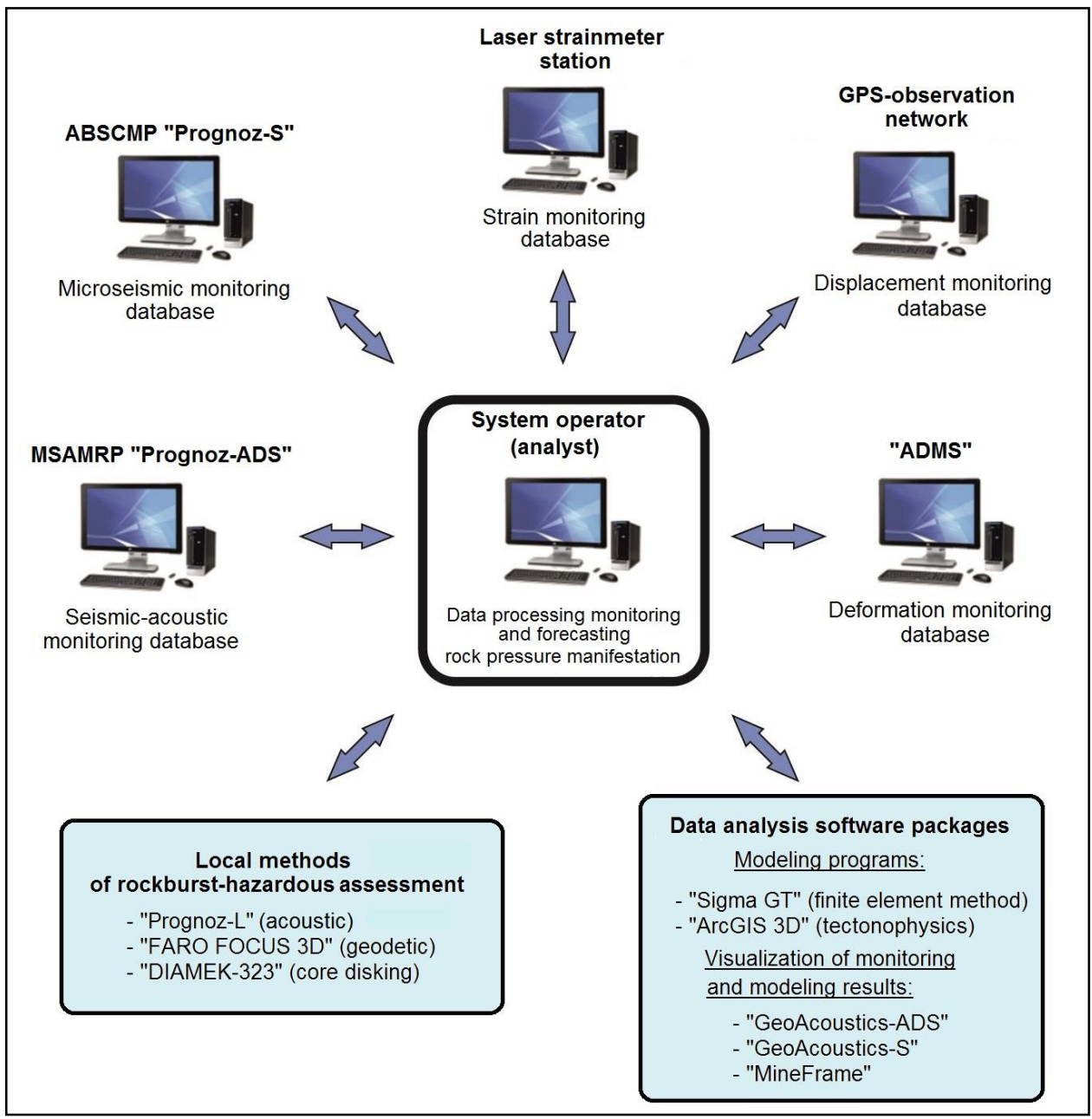

Fig. 1. - Technical means and methods of current monitoring as part of the "Geodynamic polygon Streltsovsky ore field"

Geomechanical studies conducted in the 2014-2016 period with the use of technical means SOF GDP showed a relatively high efficiency of predicting. The installation of the equipment made it possible to identify potentially rockburst-hazardous areas based on the results of comprehensive monitoring at the Streltsovskoye and Antey deposits. The presence of these zones was confirmed by methods of local assessment of the rock mass. The application of these methods allowed to solve a number of important issues related to the local safety of mining operations in complex geodynamic and geological conditions. However, the problem of geodynamic risk predict has not been solved yet.

\section{The principles of updating monitoring systems}

Analysis of the conditions of field development and monitoring results allowed to clarify and adjusting the scientific-technical, production and organizational principles of monitoring. Thus, the existing technical means of GDP are distributed unevenly over the area of SOF and fully cover only the deposits in the Central part of the ore province. 
Therefore, seismicity of technogenic origin is registered here as a result of intensive geodynamic processes in the massif (Fig.2).

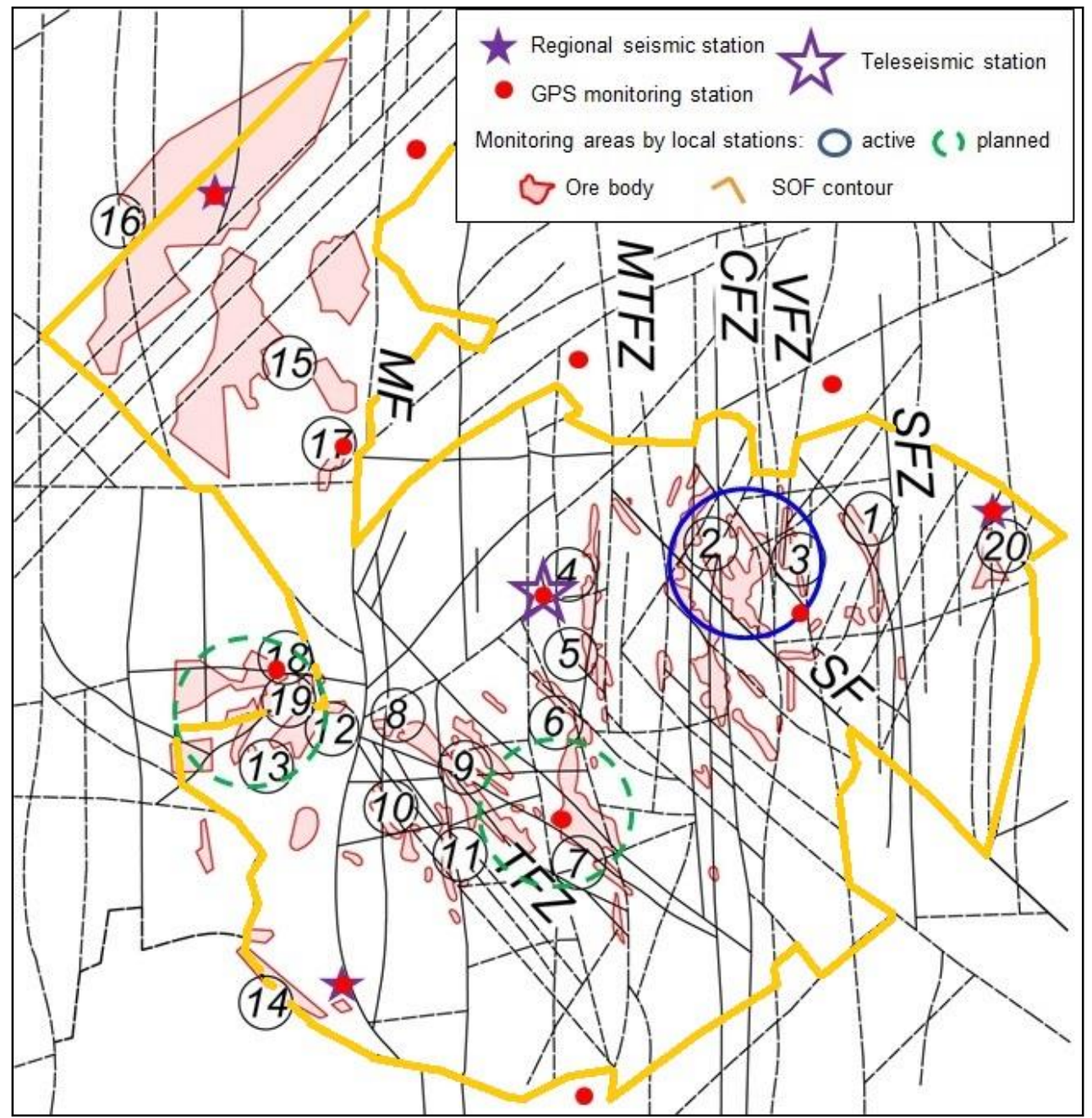

Fig. 2. Layout of monitoring technical means natural and man-made processes of the "Geodynamic polygon of the Streltsovsky ore field"

Numbers in circles indicated fields: 1 - Shirondukuevskoe; 2 - the Streltsovskoye; 3 - Antey; 4 Octyabr'skoe; 5 - Luchistoe; 6 Martovskkoe; 7 - Malo-Tulukuevskoe; 8 - Tulukuevskoe; 9 Yubileynoe; 10 - Vesennee; 11 - Novogodnee; 12 - Pyaniletnee; 13 - Krasnuy Kamen' 14 - YugoZapadnoe; 15 - Dal'nee; 16 - Polevoe; 17 - Bezrechnoe; 18 - Argunskoe; 19 - Zerlovoe; 20 Vostochno-Shirondukuevskoe. The acronym designated fault zones and faults: SFZ -

Shirondukuyskaya; VFZ - Vostochnaya; CFZ - Centralnaya; MTFZ - Malo-Tulukuevskaya; TFZ Tulukuevskaya; SF - Streltsovskyi; MF - Meridionalny.

However, the availability of the data obtained is not sufficient for both: the interpretation of natural and man-made phenomena, and for the study and understanding of the mechanism of geodynamic processes occurring in the earth's crust of the SOF area. In this regard, it is necessary to develop and expand existing approaches, methods of control and technical means on the basis of the SOF GDP already made in 2014. 
It is advisable to carry out scientific research to improve the methodological and technical equipment of the SOF GDP. This requires the integration of new methods in larger monitoring areas. The aim of the research is to predict the occurrence of geodynamic risk. On the basis of the obtained results, the justification of risk reduction methods for all developed SOF, including closed and conserved ones, will be carried out.

In the world's mining practice, such large-scale integrated studies are not mentioned. Moreover, the common of regular astronomical-geodetic, satellite, seismic, geophysical, geological, and a number of other observations aimed at the simultaneous study and monitoring of geodynamic processes in the upper part of the earth's crust should be carried out on the problem area (group of deposits or ore provinces). It is advisable to organize regular system observations on a larger part of the SOF to obtain the missing information $[14,18,19]$. Besides the available technical means, additional ones will be required (Fig.3):

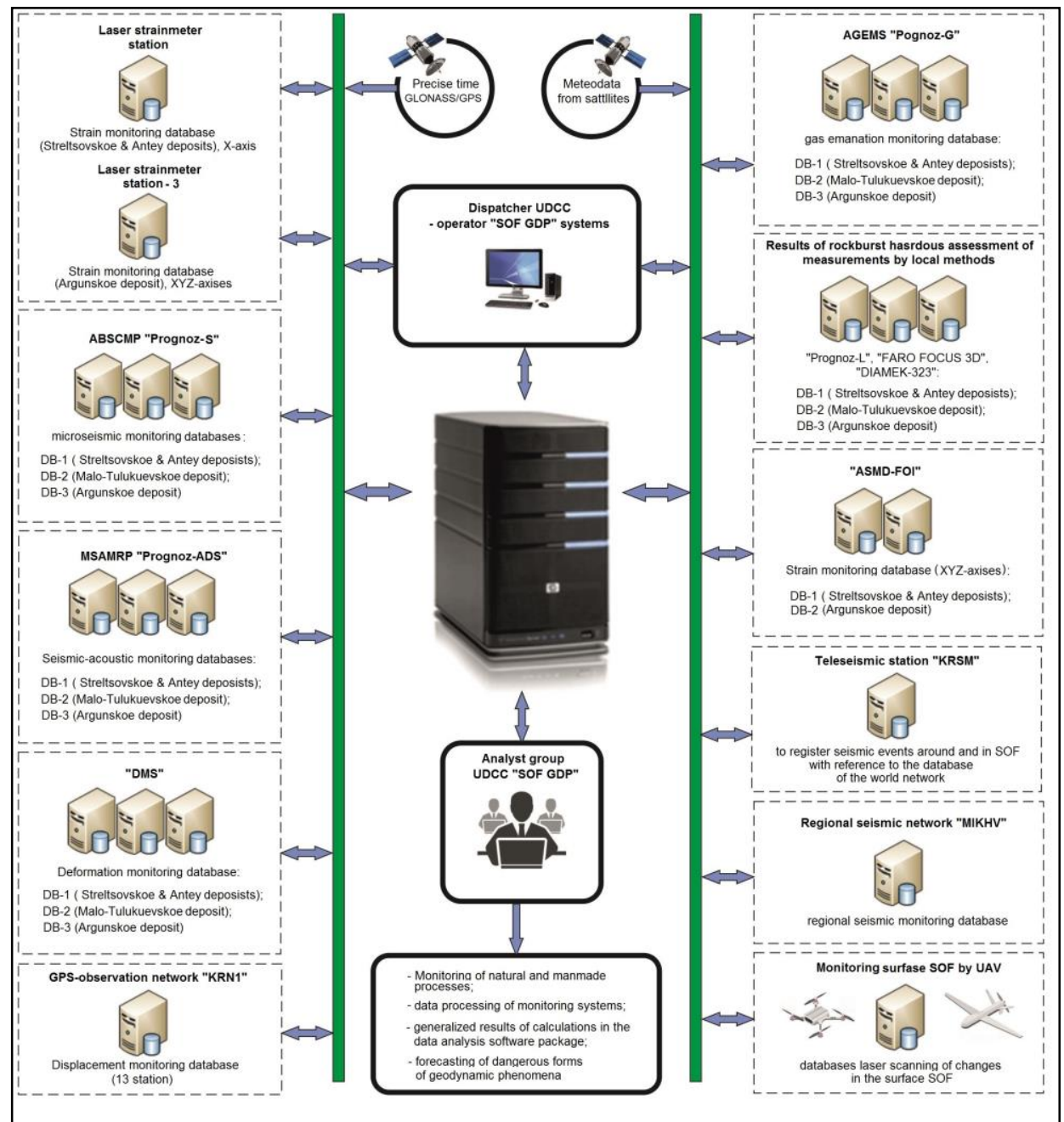

Fig. 3. - Technical means and methods of future complexed geodynamic monitoring of the Streltsovsky ore field.

- A regional seismic network of 3 stations to be located along the perimeter of the SOF (included in the seismic register stations of the unified geophysical service of the RAS), the information obtained will allow to register and locate regional earthquakes; access to the 
seismic events database of region is necessary for interpreting the results obtained by other methods.

- Teleseismic station with reference to the database of the world network; automated station, which has operational access to information about seismic events in other parts of the Earth, allows to obtain further necessary information for the interpretation of the results of the station "Laser strainmeter".

- A network of GPS-observation stations for displacement on the surface of the SOF; evenly distributed network of observation stations will allow to measure the movement of the most important geological and structural blocks and sides of the active zones of faults.

- Deformation monitoring system (DMS) located in the depth of the rock mass and near the contours of underground mine workings in areas that are under the influence of tectonic faults and ore-bearing faults; the network of observation points will allow to obtain geodetic measurements of strain and stresses in the rock mass.

- Automated gas emanation monitoring system (AGEMS) "Prognoz-G" for ore-bearing faults and active tectonic faults. In the world's mining practice, there are known facts of increasing the concentration of gases coming from the zones of geological disturbances and faults during the activation of geodynamic processes [20, 21]; the network of observation points is installed in underground mines exposed to the large tectonic disturbances.

- Automated system monitoring of deformation "ASMD-FOI" based on ultra-precise fiber-optic shoulder interferometers of the Maikelson and Mach-Tsender borehole type; the network of observation points of the system will reveal the patterns of geodynamic processes in the area of mining influence to obtain fundamentally new information about the stress-strain state of the geological environment, as well as to establish regional precursors of geodynamic phenomena.

- The system of monitoring the earth's surface of the SOF by high-precision laser scanning and detection of changes with the help of unmanned aerial vehicles (UAV); the results obtained during the regime course overflights of the territory of the SOF are used to compile a $3 \mathrm{D}$ model of the earth's crust surface, as well as to identify anomalies and changes in the geodynamic structure.

- Complex of automated monitoring systems for rockburst-hazardous MaloTulukuevskoe and Argunskoe deposits providing a reliable predict of geodynamic manifestations of rock pressure; a network of registrators, the automated systems "Prognoz ADS", "Prognoz-S" in complex with the seismic stations enable to log events in the frequency range from 0 to $12 \mathrm{kHz}$ in the rocks of the SOF.

- Data obtained from satellite systems, including the exact world time of the main server, local meteorological and geodata from the area of the SOF; the use of satellite sensing results as part of other methods is considered a perspective direction in the study of geodynamic processes [22].

Processing the multidimensional and volumetric data on monitoring measurements should be based on modern multi-level hardware and specialized software systems. In this regard, it is proposed to organize a "Unified dispatching computer center" (UDCC), with the next included tasks: remote control of the state of the whole complex of subsystems; analysis of multi parametric information about geodynamic processes in the territory of the SOF; interpretation of the results with the identification of local geomechanical processes in the depth of the rock mass, as well as fixed near underground mine workings. The UDCC hosts the master server for collecting data and storing the results of all monitoring subsystems. A group of analysts and specialists of the Center assesses the geodynamic and geomechanical state of the rock mass on the basis of the analysis of constantly updated in automatic monitoring data (as well as the results of stress-strain state modeling, the results of measurements by local and regional methods). Based on the results of the assessment, the predicting of geodynamic phenomena and dangerous forms of mountain pressure 
manifestation is carried out. The results of the predicting will allow developing the necessary measures to ensure the safety of mining operations in the ore province.

\section{Conclusions}

Implementation of the proposed innovative principles for the creation and operation of a system of integrated monitoring of multi-scale geomechanical and geodynamic processes, which will be based on the most modern scientific and technical base and the latest scientific achievements in the field of geomechanics, geodynamics, geoinformatics, systems engineering, geotechnology and other related scientific areas, will not only solve the problem of reducing the risk of man-made disasters at the facilities on the Streltsovsky ore province of PIMCU PJSC, but also create a reserve for the continuation of promising high-tech research to solve current mining problems.

The paper has been reported at the 1-st Conference "Problems of Geomechanics of Highly Compressed Rock \& Rock Massifs".

\section{References}

1. Yu.D. Bulanzhe, D.A. Lilienberg (Eds.). Integrated geodynamic testing sites: Research procedure and Results (Moscow, Nauka Publishing, 1984)

2. A.L. Pustuev, J.P. Konovalova, A.A. Martemyanov. Principles of construction of geodynamic polygons in a large-scale subsurface. Gorn. Zhurn., 1 (2012)

3. Geomechanical fields and processes: experimental and analytical studies of formation and development of focal zones of catastrophic events in mining and natural systems. (Eds. V.N. Oparin and etc.) Novosibirsk, SB RAS Publishing, 2vol. (2018)

4. A.A. Kozyrev, E.V. Kasparyan, Iu.V. Fedotova. Monitoring of natural and man-made processes in mining operations in high-stress rock massifs. Monograph. LAP Lambert Academic Publishing RU, Saarbrucken, Deutschland (2016)

5. I.Yu. Rasskazov, A.V. Gladyr, P.A. Anikin, V.S. Svyatetskiy, B.A. Prosekin. Development and modernization of the control system of dynamic appearances of rock pressure on the mines of Priargunsky Industrial Mining and Chemical Union JSC. Gorn. Zhurn., 8 (2013)

6. A.V. Gladyr, D.S. Migunov, P.A. Anikin, G.A. Kalinov, V.I. Miroshnikov. Structure of equipment of the Streltsovsky ore field testing site. MIAB Sci. and Tech. J., SI 24 (2017)

7. I.Yu. Rasskazov, G.I. Dolgikh, V.A. Petrov, V.A. Lugovoi, S.G. Dolgikh, B.G. Saksin, D.I. Tsoi Laser strainmeter in integrated geodynamic monitoring within Streltsov ore field. J. Min. Sci. 52 (2016a),

8. I.Yu. Rasskazov, B.G. Saksin, P.A. Anikin, G.P. Potapchuk, B.A. Prosekin, O.A. Is'yanov Features of dynamic manifestations of mining pressure at the Antey deposit. MIAB Sci. and Tech. J., OB 9 (2007)

9. A.V. Gladyr, V.I. Miroshnikov, Yu.I. Bolotin, A.V. Aleksandrov, P.A. Anikin, M.I. Rasskazov Technical equipment of a new generation microseismic monitoring system. MIAB Sci. and Tech. J., 5 (2012)

10. K.V. Morozov, V.I. Eckgart. Automated underground system the deformation monitoring of rock massif in the mine "Glubokii", PIMCU PJSC. MIAB Sci. and Tech. J., S7 (2015) 
11. G.I. Dolgikh, I.Yu. Rasskazov, V.A. Lugovoy, P.A. Anikin, D.I. Tsoi, V.A. Shvets, S.V. Yakovenko. The laser strainmeter in Krasnokamensk. Exp. Dev. and Tech. J., 5 (2013)

12. G.I. Dolgikh, S.G. Dolgikh, I.Yu. Rasskazov, V.A. Lugovoy, B.G. Saksin. The test results of the laser strainmeter installed in the Trans Baykal. Geol. and geoph. J., 57 (2016)

13. I.Yu. Rasskazov, G.I. Dolgikh, V.A. Petrov, V.A. Lugovoy, S.G. Dolgikh, B.G. Saksin, D.I. Tsoi Application of laser deformograph in the system of complex geodynamic monitoring in the area of Streltsovsky ore field. FTPRPI J., 6 (2016b)

14. I.Yu. Rasskazov, V.A. Petrov, A.V. Gladyr, D.V. Tyurin. Geodynamic polygon of Streltsovsky ore field: practice and prospects. Gorn. Zhurn., 7 (2018)

15. A.A. Kozyrev, I.E. Semenova, I.M. Avetisyan Creation of a numerical geomechanical model of the Antey deposit as a basis for predicting the stress-strain state of the massif. MIAB Sci. and Tech. J., 4 (2014)

16. S.V. Lukichev, O.V. Nagovitsyn, I.E. Semenova, O.V. Belogorodtsev Mine planning and design in MINEFRAME. Gorn. Zhurn., 8 (2015)

17. I.Yu. Rasskazov, D.S. Migunov, P.A. Anikin, A.V. Gladyr, A.A. Tereshkin, D.O. Zhelnin. Geoacoustic a portable device of new generation for estimation of rockburst hazard of rocks. FTPRPI J., 3 (2015)

18. A.N. Shabarov, S.V. Tsirel', K.V. Morozov, I.Yu. Rasskazov. The concept of integrated geodynamic monitoring in underground mining. Gorn. Zhurn., 9 (2017)

19. B.G.Saksin, I.Yu. Rasskazov, B.F. Shevchenko. The principle of a complex study of the current stress-strain state of the upper levels of the earth's crust of the Amur lithospheric plate. FTPRPI J., 2 (2015)

20. Iu. Fedotova, S. Zhukova. Interrelation of subsoil hydrogen emanation during bulk blasting and higher seismicity of the Khibiny massif. Proceeding on the 6th International Symposium on In-situ Rock Stress, ISRM Specialized Conference, 20-22 August, 2013, Sendai, Japan (2013)

21. A.M. Asavin, V.N. Nivin. Organization of geoecological monitoring of gas emissions in the Arctic: methods and prospects of modern wireless technologies. Arct.: Ecol. and Econ. J., 3 (2015)

22. Zh.T. Kozhaev, M.A. Mukhamedgalieva, B.B. Imansakipova, M.G. Mustafin. Geoinformation system of geomechanical monitoring of ore deposits using methods of space radar interferometry. Gorn. Zhurn., 2 (2017) 